\title{
FACTORES ASOCIADOS A LA DESERCIÓN/ RETENCIÓN DE LOS ESTUDIANTES MAPUCHE DE LA UNIVERSIDAD DE LA FRONTERA E INCIDENCIA DE LOS PROGRAMAS DE APOYO ACADÉMICO
}

\section{Contexto general del estudio}

\subsection{Educación superior en Chile}

Chile ha vivido una expansión y transformación en educación superior similar a la de otros países de América Latina; en este sentido Donoso, Donoso y Arias (2010) realizan un importante recorrido acerca de la evolución de este sector en Chile y cómo los cambios de oferta y demanda han derivado en la necesidad de generar estrategias orientadas a la retención de estudiantes en las respectivas casas de estudio.

Una de las características del sistema de educación superior de Chile es el crecimiento que ha experimentado a nivel de cobertura, impulsado por el desarrollo del sector privado principalmente a nivel universitario.

Según datos del Sistema de Información de Educación Superior (SIES) de 2011, en Chile hay 177 instituciones de educación superior con un total de 59 universidades, de ellas 25 son universidades del Consejo de Rectores (CRUCH), también llamadas «tradicionales». Dentro de las universidades del CRUCH hay 16 estatales y nueve privadas con aporte estatal. Además, hay 34 universidades privadas que no pertenecen al CRUCH.

En 2011 la matrícula total en la educación superior chilena llegó a cerca de un millón de estudiantes, de los cuales más del 65\% estudiaba en universidades. En 2012, en tanto, el sistema superó el millón cien mil estudiantes, lo que significa una cobertura del 54,9\% de la población entre 18 y 24 años. Las condiciones de la población 
estudiantil en Chile también se explican en gran medida por el nuevo perfil que ha generado el aumento de la matrícula: siete de cada diez alumnos en la educación superior chilena son primera generación en la universidad (SIES, 2012). Asimismo, según los datos de la encuesta CASEN (Ministerio de Desarrollo Social, 2011) el 69,2\% de la población estudiantil asiste a una universidad privada, mientras que solo el 30,8\% lo hace a una universidad del CRUCH. Es importante destacar que esta proporción se mantiene indistintamente del quintil socioeconómico del estudiante.

En la educación superior chilena prácticamente tres de cada diez estudiantes desertan de las instituciones a las que ingresaron en el primer año. Esta deserción es mayor en los institutos profesionales y en los centros de formación técnica, donde llega al 35\%, mientras que en las universidades este porcentaje alcanza al 25\%. La deserción de las instituciones también tiende a afectar en mayor medida a los estudiantes de nivel socioeconómico más bajo.

Las cifras de fracaso en Chile siguen siendo elevadas, afectando de manera evidente y significativa a los estudiantes de los dos primeros quintiles de ingresos (Organisation for Economic Cooperation and Development [OCDE], 2009), lo que contribuye a la reproducción de la desigualdad social, con el agravante de que muchas familias se han endeudado en cifras importantes para dar soporte financiero a los que estudian (Donoso y Cancino, 2007). Este panorama ha llevado a que se instalen de manera poco sistemática y aisladamente programas de nivelación y/o remediales en casi todas las universidades del país.

\subsection{Educación superior y pueblos indígenas}

Según los datos de la encuesta CASEN de 2009 en Chile el 6,9\% de la población se autoidentifica como perteneciente a alguno de los pueblos indígenas de Chile (el Estado reconoce a nueve), de ellos el 85\% es mapuche. La tendencia indica que la población indígena ha tendido a migrar hacia las ciudades y a no habitar en zonas rurales. Por ejemplo, en 2009 la población indígena urbana subió desde 51,7\% en 1996 a 69,4\%. Sin embargo en las zonas rurales la concentración de grupos indígenas aún es mayor que la de grupos no indígenas. 
Respecto de la pobreza, la encuesta mencionada mostró que la población indígena es más pobre que la no indígena, con $20 \%$ en esta clasificación, frente a 14,8\% de pobreza en la población no indígena.

Los pueblos indígenas en Chile han sido parte de los importantes avances en materia de cobertura educativa, tanto en educación básica y media, como en educación superior (OCDE, 2009). Si bien ha aumentado de manera importante el acceso a la educación en sus distintos niveles - preescolar, básica, media y superior-, este no ha sido homogéneo para los distintos niveles de educación, como tampoco lo ha sido al interior de los distintos grupos de la población (Ministerio de Desarrollo Social, 2011). Entre estos grupos, los descendientes de pueblos originarios han mostrado indicadores educativos consistentemente más bajos: mayor analfabetismo y menos cobertura educativa en general (Blanco y Meneses, 2011). Las diferencias en educación superior son importantes sobre todo cuando estas explican, en gran medida, las variaciones en el ingreso de las personas (Ministerio de Desarrollo Social, 2009).

Blanco y Meneses (2011) realizaron un estudio censal para conocer la situación de la población estudiantil indígena en Chile, con importantes hallazgos acerca de las características de ingreso de estudiantes indígenas a la educación superior en sus distintas modalidades, enfatizando en la importancia de las ayudas estudiantiles (becas y créditos) como un factor determinante de continuidad de estudios en este grupo étnico específico.

Por ejemplo, la población estudiantil indígena representa un $6,7 \%$ de la población general. Los estudiantes indígenas no tienen notas de enseñanza media inferiores a sus pares no indígenas y se esperaría por ello que al salir del nivel tuvieran condiciones similares; pero muy por el contrario, los estudiantes indígenas tienden a rendir en menos proporción la PSU y a obtener puntajes significativamente menores (50 puntos menos que el promedio nacional). Esto indica que las expectativas de inclusión educativa para los alumnos indígenas después de cuarto medio son inferiores y que, incluso en aquellos que rinden la prueba, sus resultados terminan excluyéndolos (Blanco y Meneses, 2011). 
Igual como ocurre con otros grupos sociales, entre los indígenas también la educación es un dispositivo para superar de manera definitiva situaciones de pobreza. La educación representa un importante factor de movilidad social y de inserción laboral. Sin embargo, la educación superior ha sido una sumatoria de aspiraciones y demandas históricamente frustradas para esta población (Bello, Willson, González y Marimán, 1997). En Chile el ingreso de la población indígena a la educación superior es un fenómeno reciente y se produce en un escenario de alta vulnerabilidad social, sumado a situaciones de discriminación, traduciendo el acceso a la universidad como el distanciamiento definitivo de su origen étnico (Saiz, 2003), que no se logra disminuir con el paso de los años, ya que los estudiantes mapuche arrastran un desempeño deficiente y tienden a necesitar más semestres para lograr su titulación (González, 2006).

\subsection{Deserción en la educación superior}

El desarrollo que ha experimentado el sistema de educación superior en Chile ha permitido a un nuevo grupo de jóvenes acceder a la educación superior. Sin embargo, este nuevo fenómeno ha traído consigo el desafío de retener a este grupo de estudiantes en las instituciones y/o en los programas de estudio a los que ingresaron.

En este sentido, el SIES indica que la retención al primer año de 2007 fue de 62,5\% para los centros de formación técnica, de 58,1\% para los institutos profesionales y de $75 \%$ para las universidades; mientras que al 2010 la retención aumentó para los tres tipos de instituciones de educación superior, alcanzando 64,3\% de retención al primer año para los centros de formación técnica, $64,3 \%$ para los institutos profesionales y $77 \%$ para las universidades (Ministerio de Educación [Mineduc], 2012).

Es importante destacar que al observar los datos de retención al primer año en las cohortes 2008, 2009 y 2010, los quintiles 1 y 2 mostraron índices más bajos. Donde sí se observan importantes diferencias en cuanto a la retención es respecto del establecimiento de origen, ya que en el 2007 los estudiantes que provenían de colegios municipales presentaron una tasa de retención al primer año de $68,1 \%$, mientras que aquellos que provenían de establecimientos 
particulares pagados presentaron una tasa de retención al primer año de 80,4\%. En el 2010 la brecha para la retención se acortó levemente, con $70,1 \%$ y $80,4 \%$, respectivamente (Mineduc, 2012).

\subsection{Teorías explicativas de la deserción para la educación superior}

El presente apartado pretende ser un resumen basado en el trabajo realizado por Himmel (2002), Donoso y Schiefelbein (2007), Díaz (2008) y Barrios (2011) de aquellas teorías que presentan diferentes modelos explicativos de la deserción, reuniendo así los aportes teóricos más relevantes para la realidad chilena.

Las teorías psicológicas centran el foco de la deserción en las características psicológicas de la persona que decide desertar o continuar con sus estudios. En este sentido, generalmente consideran las variables individuales que representan características propias de cada estudiante. Ethington (1990) se basó en estos modelos e incorporó elementos de las conductas de logro de Eccles et al. (1983), encontrando empíricamente que el rendimiento académico previo afecta los resultados futuros de los estudiantes, pues influye sobre la percepción que ellos tienen de sus capacidades e influye en la forma en que enfrentan las dificultades académicas, las metas que se fijan y las expectativas de éxito que tienen.

Desde la perspectiva económica se privilegia la idea de que los alumnos permanecen en la educación superior en la medida en que los beneficios, tanto sociales como económicos que perciben por ser estudiantes, sean mayores que los costos derivados de ello, por tanto se evalúa el costo-beneficio de estudiar frente a otra actividad; también se relaciona con la entrega de subsidios para la educación y la percepción que tiene el estudiante respecto de su capacidad para asumir los costos asociados a sus estudios.

La perspectiva organizacional propone que la deserción depende de las características de la institución de educación superior $y$, ya que estas pueden ser modificadas, bien pueden influir de forma importante en la deserción. Por lo tanto elementos como la calidad 
de los profesores (Braxton, Milem y Sullivan, 2000) y la experiencia de estos en la sala de clase influyen de manera importante en el abandono de la educación superior. Tillman (2002), por su parte, plantea que factores como los seguros de salud, las actividades deportivas y culturales, la disponibilidad de libros, la infraestructura y otros indicadores como el número de alumnos por profesor también influyen de forma significativa en la retención de estudiantes. Estudios más recientes (Mineduc, 2012) plantean que la acreditación institucional correlaciona significativamente con la retención de estudiantes.

\subsubsection{Resultados de modelos empíricos}

Sin lugar a dudas, uno de los trabajos más relevantes en estas materias es el propuesto por Himmel (2002), el que plantea una discusión de los modelos conceptuales que permite la comprensión del fenómeno de la deserción.

En la Universidad de Antofagasta, Reyes et al. (2007) realizaron un estudio para determinar qué factores influyen sobre el rendimiento académico de los alumnos de Ingeniería. Mediante una regresión logística, los autores modelaron una herramienta para predecir el éxito de los estudiantes durante el primer semestre de la carrera, considerando factores como las expectativas de los alumnos respecto de su rendimiento, la importancia que le asignan a los resultados y la valoración del esfuerzo de cada uno, además de variables como las notas de enseñanza media y los puntajes de la PSU de Lenguaje, Matemática y Ciencias. Los autores descubrieron que las notas de enseñanza media y los puntajes PSU de Matemática y Ciencias fueron los más significativos para predecir la aprobación de todas las asignaturas del primer semestre de la carrera.

Saldaña y Barriga (2010), en tanto, en un estudio realizado con estudiantes de la carrera de Ingeniería Civil en la Universidad Católica de la Santísima Concepción, concluyeron que previamente al ingreso a la universidad, los factores que más impactaban en la deserción eran los ingresos familiares y el puntaje obtenido por el alumno en la PSU de Lenguaje y en la de Matemática. Una vez que el 
estudiante ingresaba a la universidad, las variables que se sumaron a las anteriores fueron el promedio semestral del alumno, la cantidad de créditos aprobados que el estudiante acumulara en cada semestre y el porcentaje de financiamiento que había obtenido para cubrir los costos de arancel anual de carrera.

Al respecto, en los últimos años también destaca el trabajo de Barrios et al. (2011), quienes estimaron un modelo de deserción de las universidades chilenas en el que se incluyeron variables demográficas, socioeconómicas, académicas e institucionales. Se contemplaron además variables que indicaban si los estudiantes habían recibido algún tipo de beneficio socioeconómico, distinguiendo entre las becas y los dos tipos de crédito que administraba el Estado. En este trabajo se estudió la relación entre la deserción y estas variables, centrando la discusión en el papel de los beneficios estudiantiles y su focalización. Aunque a partir de los modelos estimados no se concluye una causalidad, sí se encuentra una relación positiva entre los beneficios y la permanencia de los alumnos en el sistema. Asimismo, se definió que esta relación era más estrecha en el caso de los estudiantes de menores ingresos.

Otro estudio realizado por Acuña (2012) muestra que los quintiles PSU del establecimiento (puntaje PSU promedio obtenido por el establecimiento, ordenado de menor a mayor en 5 grupos) tienen una correlación mayor con la deserción de los estudiantes, que los quintiles del alumno (puntaje PSU promedio obtenido por el estudiante, ordenado de menor a mayor en 5 grupos). De lo que se deduce la importancia que tienen los establecimientos de educación secundaria sobre el rendimiento posterior de los estudiantes, ya que a pesar de controlar los factores relacionados con los establecimientos de educación superior, las variables institucionales más sólidas siguen siendo aquellas relativas a la calidad institucional, como es el caso del quintil del establecimiento en mediciones como el SIMCE o la PSU.

El centro de estudios del Ministerio de Educación (Mineduc, 2012) también muestra importantes resultados para identificar las variables asociadas a la deserción, basándose principalmente en la 
propuesta metodológica planteada por Barrios et al. (2011), entre ellas la acreditación de la institución, la vocación (definida por el número de preferencia del estudiante al elegir su carrera) y la importancia que adquieren las ayudas estudiantiles (becas y créditos), las que son relevantes en la permanencia dentro de la educación superior.

Finalmente, Barrios (2013) concluye que las mujeres y los estudiantes solteros tienen una menor probabilidad de desertar de la educación superior, igual que aquellos alumnos con mejores notas de egreso de la enseñanza media y un mayor puntaje PSU; por su parte, los estudiantes provenientes de establecimientos municipales tienen mayores probabilidades de desertar que los estudiantes que salen de establecimientos particulares pagados; finalmente el autor plantea que los instrumentos de financiamiento reducen las probabilidades de deserción y que la efectividad de estos es mayor cuanto menores son los ingresos de quien los recibe, por lo que la focalización de estas ayudas económicas en los estudiantes pertenecientes a los quintiles más bajos del país es consistente.

\subsection{Deserción/retención de estudiantes no tradicionales en educación superior}

Las teorías expuestas dan cuenta de la importancia de las características de ingreso a la educación superior como factores relevantes para explicar la deserción, evidenciando con ello que las variables socioeconómicas siguen siendo predictivas para el éxito académico. Sin embargo, es importante conocer los estudios que abordan la deserción/retención de estudiantes no tradicionales en educación superior que, como plantean algunos autores, corresponden a grupos minoritarios de tipo étnico, racial y de género, entre otros. Para este estudio, además, se incorporarán investigaciones de estudiantes «vulnerables», entendiéndose por esto aquellos que poseen gran parte de las variables que predicen la deserción.

La mayor parte de la literatura en este ámbito corresponde a estudios realizados en Estados Unidos, producto de la gran cantidad de población negra e inmigrante que hoy accede a la educación superior. Tal es el caso de Abatte (2008), quien en un estudio descriptivo de estudiantes no tradicionales en la educación superior de EE.UU. 
plantea que este grupo alcanza el 32\% de la población universitaria americana y que es muy necesario realizar acciones que permitan apoyar el proceso de ingreso y permanencia dentro del sistema, ya que poseen tasas de titulación más bajas que el resto de los estudiantes, independientemente de la edad y del grupo socioeconómico al que pertenecen. Esta autora plantea también que gran parte de sus dificultades de ingreso y permanencia en la educación superior en los EE.UU. tienen relación con las habilidades de lectoescritura, porque ellos han estado expuestos de forma tardía al lenguaje predominante utilizado en las aulas universitarias, por lo que cuentan con menos vocabulario y familiaridad con el estilo formal en el que muchos académicos dictan sus cátedras.

Desde otra perspectiva, algunos autores destacan la relevancia de los factores individuales en la retención universitaria de estudiantes vulnerables. Así, Goldfinch y Hughes (2007) y Catterall (1998) plantean la importancia del autocontrol, autoestima, optimismo y confianza en las propias capacidades como variables de gran importancia para explicar la retención en este grupo de estudiantes.

En esta misma línea, la literatura indica que los estudiantes vulnerables desarrollan una comprensión de la adversidad, visualizando las posibilidades de éxito. De igual modo se han ampliado los estudios de retención que incorporan el concepto de «resiliencia» para explicar la permanencia de los grupos vulnerables. Reed-Victor y Stronge (2002), por ejemplo, sostienen que los estudiantes que han vivido adversidades, o bien, que se definen como vulnerables logran desarrollar y usar los recursos disponibles para sobreponerse a tales circunstancias. Complementariamente, González (2007) plantea que en el caso de los estudiantes mapuche, estos utilizan todos los recursos administrativos disponibles para permanecer en la educación superior.

En este sentido, los estudiantes que desarrollan conductas resilientes logran permanecer de manera exitosa en el sistema universitario, porque cuentan con una visión proactiva y consciente de las barreras y oportunidades que dicho sistema les ofrece (Masten, 1994). De igual forma, González (2007) plantea que los estudiantes 
mapuche desarrollan una mayor persistencia para continuar en la universidad, al menos durante los años iniciales, lo que podría obedecer a una mayor valoración de la educación universitaria y/o a la percepción de inexistencia o escasez de futuras oportunidades de estudio que sean comparables con la que se tiene en ese momento. Consistentemente con estos planteamientos, Canales y De los Ríos (2009) indican que los alumnos que logran progresar en el sistema universitario hacen uso efectivo de la mayoría de los soportes o recursos dispuestos para enfrentar las dificultades dentro del sistema educativo. La interacción entre las capacidades personales, los apoyos familiares, los recursos sociales (redes) y los soportes institucionales permite explicar la permanencia de ellos en la universidad.

La diferencia cultural, en especial el modelo de educación mapuche, constituye uno de los factores que explican las dificultades que presentan estos estudiantes durante su proceso de formación universitaria, el que en variados aspectos entra en contradicción con la educación tradicional. En efecto, la educación mapuche se caracteriza por la reproducción oral de conocimientos y creencias, las cuales se regulan mediante un sistema de normas y reglas que operan desde la cotidianidad en todos aquellos actos de convivencia social. El aprendizaje se desarrolla por medio de la observación y reproducción de los actos y los contenidos más abstractos se transmiten y adquieren en el gvlam o conversación (Bello et al., 1997).

Entre los factores personales se señalan los siguientes:

a. Las diferencias en el nivel de conocimiento disciplinario básico (en especial, en matemática, razonamiento y análisis, comprensión lectora y resolución de problemas). Este aspecto se relaciona con el hecho de que, en general, la mayoría de estos estudiantes proviene de establecimientos técnico-profesionales, localizados en pueblos pequeños, rurales y con bajos indicadores de calidad educativa.

b. La insuficiencia de redes de apoyo sociales y familiares, producto de la distancia respecto de los espacios de socialización y convivencia, con la consiguiente sensación de desarraigo.

c. La falta de apoyo, particularmente en términos económicos, lo que en muchos casos influye en condiciones deficientes para vivir 
y estudiar, especialmente en aquellos estudiantes que residen en hogares indígenas (residencias estudiantiles).

d. Las dificultades de los estudiantes para organizar su tiempo de estudio y enfrentar los ritmos y demandas académicas en la universidad (González, 2007).

\subsection{Apoyo académico en Chile}

En Chile las universidades privadas son las que principalmente ofrecen programas de inserción y apoyo académico para promover el acceso de estudiantes de vulnerabilidad social y corregir los rezagos educativos de aquellos que ingresan a la vida universitaria con bajos niveles de preparación académica. En una encuesta realizada por el Centro de Microdatos de la Universidad de Chile (2008), el 46,6\% de las universidades privadas declara tener estos programas en el 100\% de sus carreras. En cambio, en las universidades del CRUCH solo el $11,6 \%$ cuenta con iniciativas de este tipo, aunque cada vez son más las instituciones que adoptan políticas inclusivas en combinación con un programa de inserción.

En Chile, estos programas abarcan instrumentos tales como talleres en habilidades de estudio, apoyo psicoeducativo y nivelación de conocimientos. Debido a que estos apoyos son cada vez más comunes dentro de las universidades ello se vuelve especialmente relevante en el caso de los estudiantes sin padres universitarios, quienes no cuentan con el mismo capital cultural que sus pares provenientes de familias con tradición universitaria (Canales y De los Ríos, 2009). Aunque la parte remedial es importante para mejorar el nivel de preparación académica de las nuevas generaciones de estudiantes universitarios, esto no es suficiente para asegurar la permanencia y el éxito académico de los estudiantes más vulnerables (Grimes y David, 1999; Wilmer, 2008).

En la Universidad Bernardo O'Higgins, por ejemplo, existe el Programa de Apoyo al Rendimiento Estudiantil (PARES), enfocado en atención psicoeducativa individual. El objetivo de esta iniciativa es el desarrollo de estrategias de aprendizaje metacognitivas y autorreguladas que sirvan a los estudiantes no solo para su formación 
académica, sino también en su vida social y profesional (Assef y Becerra, 2010). También se destaca la estrategia de retención de estudiantes de la Facultad de Ciencias Físicas y Matemáticas de la Universidad de Chile, la que tenía altas tasas de deserción en la década de los ochenta y que dio origen a esta iniciativa. La Universidad del Bío Bío, mediante el Convenio de Desempeño, diseñó un programa de reforzamiento focalizado en estudiantes de los primeros quintiles y también se puede mencionar el trabajo realizado por el Propedéutico de la Universidad de Santiago de Chile.

Por su parte la Pontificia Universidad Católica de Chile (PUC), en su Centro de Apoyo al Rendimiento Académico (CARA), ofrece varios servicios de inserción y apoyo académico que incluyen talleres de estrategias de estudio, ejercicios para mejorar la autoestima y un programa remedial específico para alumnos con mayores dificultades académicas (Seguel, 2005). Los servicios del CARA se dirigen específicamente a los alumnos de alta vulnerabilidad social y/o con mayor riesgo de deserción, como por ejemplo los estudiantes que ingresan a esta universidad por medio del Programa Talento + Inclusión y que tienen trayectorias formativas y características socioafectivas muy distintas de las del estudiantado de ingreso regular de esta institución.

En la Universidad de La Frontera (UFRO) se han desarrollado programas de apoyo académico desde hace casi una década y entre ellos destaca el Programa de Apoyo a la Adaptación Universitaria (PAAU), cuyo objetivo es ayudar a los estudiantes en su mejor desempeño académico desde una mirada psicológica y pedagógica, con énfasis en el rendimiento en asignaturas de alta repitencia, mediante talleres remediales, ayudantías y tutorías. Asisten a esta iniciativa todos los estudiantes de la UFRO indistintamente de su origen étnico.

Por otra parte, desde el año 2012 se encuentran en ejecución dos iniciativas que están directamente relacionadas con el apoyo académico a estudiantes vulnerables. Ambos proyectos han sido financiados por el Ministerio de Educación y forman parte del Programa de Nivelación Fondo de Fortalecimiento de universidades 
pertenecientes al CRUCH, cuyo objetivo es generar las condiciones institucionales para incrementar los capitales sociales y culturales de los estudiantes vulnerables de la educación superior.

1.6.1 Programa Rüpü de apoyo académico para estudiantes mapuche, UFRO

Surgido en 2004, en colaboración con la Fundación Ford por medio de la línea de trabajo para el Cono Sur Pathways to Higher Educations, el Programa Rüpü (camino en mapuzungun) tiene por objetivo aumentar las probabilidades de éxito de los estudiantes mapuche en la formación de pregrado y mejorar sus posibilidades de continuar estudios de posgrado (González, 2007). Desde su creación el proyecto asume un doble desafío: por una parte visibilizar y sensibilizar a la comunidad académica y universitaria respecto de la situación de desventaja inicial $y$, por tanto, de la falta de acceso a iguales oportunidades que afecta a un grupo significativo de la población estudiantil; y, por otra, generar las acciones necesarias para revertir tal situación en el desarrollo de estrategias de apoyo tanto en lo académico como en lo cultural, de modo que ellas fortalezcan las expectativas de éxito académico e identidad de estos estudiantes.

El área académica del programa tiene por objetivo promover la participación de los estudiantes en actividades que faciliten su desempeño académico y está orientada hacia la nivelación y apoyo en la adquisición de conocimientos básicos para mejorar el rendimiento en asignaturas específicas, lo que se logra con talleres de computación, comunicación, técnicas de estudio, técnicas de lectura veloz, talleres de oratoria y un programa de tutorías especializado.

Por otra parte, el área sociocultural de dicha acción tiene como propósito apoyar el desarrollo socioafectivo de los estudiantes mapuche, para fortalecer los recursos personales que les posibiliten enfrentar de manera exitosa la vida universitaria en general. Para ello, se realizan actividades dirigidas a facilitar la inserción universitaria y a fomentar la identidad cultural mediante talleres de desarrollo socioafectivo, relaciones interpersonales, autoestima, lengua y cultura mapuche; y otras más específicas, entre las que se cuentan: 
- Foros (sociedad y cultura mapuche).

- Eventos (cine, encuentros, ferias, actividades deportivas).

- Iniciativas estudiantiles.

El Programa Rüpü se constituye como una intervención culturalmente sensible que asume que la educación debe ir más allá de la tolerancia y la comprensión paternalista en el marco de una sociedad plural, ya que, cuando la diferencia se plantea aislada de la igualdad, se generan mayores desigualdades (Elboj et al., 2000).

Para ello, la intervención se inserta en la perspectiva sociocultural del aprendizaje, la que asume que este ocurre en un contexto social en el que la construcción de la intersubjetividad es un elemento central, pues gracias a la actividad conjunta se crea un terreno socialmente compartido. La interacción social hace posible, pues, la ampliación y la transformación de los sistemas cognitivos, en tanto que el pensamiento compartido proporciona la posibilidad de participar en un proceso conjunto de toma de decisiones en el que los involucrados se pueden apropiar posteriormente de aquello que han construido con otros (Rogoff 1993, citado en González, 2007).

Las acciones educativas derivadas de este enfoque permiten lograr el desarrollo de habilidades sociales y cognitivas que favorecen, además, el desempeño en contextos sociales mayores, cuestión que resulta altamente relevante en el caso de los estudiantes mapuche. Además, la construcción de espacios colectivos en función de la pertenencia étnica permite fomentar los procesos de identidad social y cultural y asumir una visión compartida de las problemáticas que como estudiantes universitarios mapuche deben enfrentar, lo que también responde a necesidades altamente sentidas por este grupo. De este modo, se propicia la búsqueda de soluciones conjuntas y colectivas y se asume un rol activo en el propio aprendizaje, porque favorece el desarrollo de sentimientos de autoeficacia.

El impacto de estas actividades se ha evaluado de forma genérica solo apuntando hacia las notas de titulación, donde efectivamente los estudiantes mapuche que han participado en el programa muestran logros más altos que los estudiantes mapuche que no lo han hecho 
y que los estudiantes no mapuche (Navarrete y Candia, 2011). La deficiencia de esta evaluación es que se centra solo en los estudiantes que han logrado concluir sus estudios, dejando de lado a aquellos que abandonaron su trayectoria académica.

Estudios de Tinto (1975), Catterall (1998) y Goldfinch y Hughes (2007) demuestran que los programas de inserción y apoyo académico que incluyen elementos tales como la nivelación de conocimientos, las estrategias de estudio y el desarrollo personal están altamente relacionados con la permanencia de sus estudiantes en la universidad. Este efecto se produce especialmente en el caso de los estudiantes de alta vulnerabilidad social, quienes suelen tener niveles inferiores de preparación académica y, además, a menudo sufren de falencias socioafectivas como una baja autoestima, factores que influyen negativamente en la retención.

\subsection{Acerca de la Universidad de La Frontera}

De acuerdo con el Informe de Autoevaluación Institucional 2013, la Universidad de La Frontera se encuentra inserta en la Región de La Araucanía, la que tiene uno de los más bajos índices de desarrollo humano del país. Atiende a una sociedad multicultural, en un territorio cuya economía ha logrado incorporar un valor agregado marginal a sus productos y en donde sus usuarios, tanto los reales como los potenciales, revelan carencias económicas y educacionales.

Lo anterior se manifiesta en una alta vulnerabilidad socioeconómica de los estudiantes de esta universidad, ya que el $71 \%$ de su población estudiantil pertenece a los quintiles 1, 2 y 3; el 83\% de ellos obtiene ayuda financiera para solventar sus estudios; el $81 \%$ proviene de la Región de La Araucanía y cuenta con estudios en colegios públicos o subvencionados (91\%, aproximadamente). Estas condiciones de entrada definen, entonces, un grupo social y académicamente carenciado que demanda y requiere oportunidades para aprovechar sus talentos y capacidades inexplotadas.

Asimismo, los estudiantes que se incorporan a la universidad se caracterizan por tener un nivel muy heterogéneo en cuanto a su formación y condiciones de educabilidad, derivadas de la enseñanza 
media, lo que se manifiesta en el puntaje de ingreso. El nivel promedio de PSU para el año 2013 fue de 588 puntos (con un máximo de 798 y un mínimo de 476), mientras que el promedio de PSU por quintil fue el siguiente:

- Quintil 1: 566

- Quintil 2: 583

- Quintil 3: 589

- Quintil 4: 597

- Quintil 5:620

Adicionalmente, la UFRO presenta la singularidad de tener una notoria presencia de matrícula de estudiantes con ascendencia mapuche declarada: para el año 2013, por ejemplo, de 8.640 estudiantes de pregrado matriculados, 1.863 de ellos declaró tener dicha ascendencia, es decir, el 22\%.

El ingreso de estudiantes mapuche se ha ido incrementando notablemente durante los últimos años: en 2004 solo 15\% de los alumnos que ingresaron a primer año declaraba tener ascendencia mapuche, mientras que al año 2013 el 24\% de los estudiantes de ingreso a primer año declaró tener dicha ascendencia.

Por otra parte, se pueden observar las diferencias notables que expresan los puntajes de PSU de ingreso para el año 2013 por parte de los estudiantes mapuche (571 puntos) en relación con los estudiantes sin ascendencia mapuche declarada (593 puntos), los que reflejan las inequidades constantes a lo largo de los años respecto del ingreso a la universidad. Esto se torna más complejo cuando se considera que del total de estudiantes mapuche de la universidad el $77 \%$ de ellos pertenece al quintil 1, 2 y 3 en comparación con el 59\% de los estudiantes no mapuche que pertenecen a los mismos quintiles (desde el 2008 al 2013).

En términos de retención de estudiantes mapuche para las cohortes 2009 a 2012, la retención para el primer año oscila entre el $87 \%$ y el $80 \%$; solo en la cohorte 2012 se puede observar que la retención de los estudiantes mapuche supera a la retención institucional al primer año. 

MAPUCHE DE LA UNIVERSIDAD DE LA FRONTERA E INCIDENCIA DE LOS PROGRAMAS DE APOYO ACADÉMICO - S. Navarrete, R. Candia, R. Puchi

Tabla 1: Retención de estudiantes al primer año

\begin{tabular}{|l|l|l|l|l|}
\hline Retención primer año & Cohorte 2009 & Cohorte 2010 & Cohorte 2011 & Cohorte 2012 \\
\hline Universidad & $84 \%$ & $83 \%$ & $82 \%$ & $84 \%$ \\
\hline Estudiantes mapuche & $80 \%$ & $82 \%$ & $80 \%$ & $87 \%$ \\
\hline
\end{tabular}

Fuente: Dirección de Análisis y Desarrollo Institucional, Universidad de La Frontera.

1.8. Características de ingreso de estudiantes mapuche de los quintiles 1,2 y 3

Se presentan a continuación algunos datos descriptivos de los estudiantes de la UFRO pertenecientes a los tres primeros quintiles, con el fin de comparar los puntajes de PSU entre los grupos de estudiantes con ascendencia mapuche y aquellos que no pertenecen a este grupo.

Tabla 2: Puntaje promedio de PSU por régimen de estudios de enseñanza media

\begin{tabular}{|l|c|c|c|c|}
\hline Estudiantes UFRO & Municipal & P. Subvencionado & P. Pagado & Promedio \\
\hline Con ascendencia mapuche & 571,4 & 577,8 & 654,8 & 574,8 \\
\hline Sin ascendencia mapuche & 580,4 & 593,6 & 636,2 & 588,2 \\
\hline
\end{tabular}

Fuente: Dirección de Análisis y Desarrollo Institucional, Universidad de La Frontera.

Como se observa en la Tabla 2, los estudiantes mapuche obtienen puntajes PSU de ingreso más bajos que los estudiantes no mapuche pertenecientes a los mismos quintiles y que provienen de establecimientos municipalizados, particulares subvencionados o particulares pagados.

Tabla 3: Puntaje promedio PSU por régimen de estudios de enseñanza media en estudiantes mapuche según participación

\begin{tabular}{|l|c|c|c|c|}
\hline Estudiantes UFRO con ascendencia mapuche & Municipal & P. Subvencionado & P. Pagado & Promedio \\
\hline Participantes Rüpü & 566,0 & 562,7 & 638,0 & 565,3 \\
\hline No participan & 572,2 & 579,4 & 663,1 & 576,0 \\
\hline
\end{tabular}

Fuente: Dirección de Análisis y Desarrollo Institucional, Universidad de La Frontera.

Sin embargo, al hacer la comparación entre los mismos grupos, segmentando entre los estudiantes mapuche que participan en el Programa Rüpü y los que no lo hacen se puede observar que los participantes obtuvieron puntajes PSU más bajos que el resto de los estudiantes mapuche no participantes y también que aquellos estudiantes que no poseen ascendencia mapuche. 
Tabla 4: Evolución puntaje promedio PSU de ingreso por régimen de estudios de enseñanza media en estudiantes mapuche según participación por quintiles 1, 2 y 3

\begin{tabular}{|l|c|c|c|c|c|c|}
\hline \multirow{2}{*}{ Ascendencia étnica } & \multicolumn{7}{|c|}{ Cohortes } \\
\cline { 2 - 7 } & 2008 & 2009 & 2010 & 2011 & 2012 & 2013 \\
\hline Con ascendencia mapuche & 572,3 & 579,2 & 580,6 & 580,5 & 568,2 & 566,7 \\
\hline Participantes Rüpü & 552,2 & 575,9 & 559,9 & 564,2 & 569,2 & \\
\hline No participan & 578,1 & 580,1 & 584,2 & 582,6 & 568,2 & \\
\hline Sin ascendencia mapuche & 588,7 & 591,9 & 594,1 & 588,9 & 580.6 & 582,4 \\
\hline
\end{tabular}

Fuente: Dirección de Análisis y Desarrollo Institucional, Universidad de La Frontera.

Por último, tal como se describe en la tabla precedente, los estudiantes mapuche han obtenido constantemente puntajes PSU más bajos que aquellos que no lo son. Del mismo modo, los estudiantes mapuche que participan en el Programa Rüpü obtienen puntajes PSU más bajos que los estudiantes mapuche que no participan y que aquellos que no poseen ascendencia mapuche.

\section{Pregunta de investigación considerada para el estudio}

Atendiendo a los antecedentes teóricos expuestos hasta aquí, la pregunta de investigación es la siguiente: ¿cuáles son los factores que influyen en la retención de los estudiantes de la Universidad de La Frontera, ponderando el factor de origen étnico de ascendencia mapuche declarada y la influencia que puede tener la participación en el programa Rüpü?

\subsection{Metodología del estudio}

\subsubsection{Tipo de investigación y datos}

Por las características del diseño propuesto se trata de una metodología cuantitativa de tipo explicativo bajo un diseño cuasiexperimental con grupo de control. La selección de los sujetos se realizó considerando aquellos que ingresaban a las carreras de la Universidad de La Frontera en las cohortes 2006 al 2011 como estudiantes regulares. La elección de estas cohortes se debe al inicio del programa y a que el tipo de estudio (permanencia en la universidad) requiere de un tiempo de seguimiento. 
La obtención de la información provino de los registros del Programa Rüpü y de los registros académicos propios de la universidad.

Debido a fines prácticos se seleccionaron estudiantes mapuche de las Facultades de Ingeniería, Ciencias, Ciencias Sociales y Educación y de Ciencias Agropecuarias y Forestales, con lo que se pretende controlar la heterogeneidad entre los grupos, ya que se trata de facultades que concentran el mayor número y proporción de estudiantes participantes del Programa Rüpü.

\subsubsection{Descripción de las variables}

A continuación se describen las variables consideradas para el estudio.

a. Retención al primer año. Porcentaje de estudiantes que ingresan en un año determinado y que están matriculados en abril del año siguiente. A modo de ilustración, para la cohorte de ingreso 2010 la retención al primer año se calcula en abril de 2011.

b. Retención al tercer año. Porcentaje de estudiantes que ingresan en un año determinado que están matriculados en abril, medido a los tres años de haber ingresado a la universidad. A modo de ilustración, para la cohorte de ingreso 2009 la retención al tercer año se calcula en abril de 2012.

Los datos utilizados en el estudio consideran las cohortes de ingreso del año 2006 a la de 2011, ya que para estas cohortes es posible tener los datos de quintil de ingreso y, a su vez, los de retención al primer año para estas seis cohortes. Sin embargo, para la retención al tercer año se considerarán los datos de las cohortes 2006 a la cohorte 2010.

c. Ascendencia mapuche declarada. Estudiantes que al momento de matricularse en la universidad señalan que tienen ascendencia mapuche. Los estudiantes de la Universidad de La Frontera, al matricularse deben llenar el Formulario Integrado de Admisión (FIA), en el que se les pregunta si tienen ascendencia mapuche. Sobre la base de estas respuestas es posible identificar a los estudiantes mapuche de la universidad. 
d. Porcentaje de asignaturas aprobadas. Este indicador se calcula para el primer y tercer año y corresponde al total de asignaturas aprobadas respecto del total de asignaturas cursadas.

e. Porcentaje de horas aprobadas. Cada asignatura que cursa un estudiante tiene un número determinado de horas; para cada estudiante se suman las horas de las asignaturas aprobadas respecto de la sumatoria de horas del total de las asignaturas cursadas.

f. Promedio ponderado semestral. Este promedio considera al primer y al tercer año y contempla la nota obtenida por el total de horas de la asignatura y, luego, todo ello se divide por el total de horas cursadas en el semestre. Este promedio ponderado toma en consideración el peso en horas de cada asignatura.

g. Avance curricular. Indica el avance real del estudiante en función de lo establecido en su plan de estudio, en el tiempo que corresponde. En lo práctico, si nos situamos en el avance curricular para los estudiantes de primer año, ello implica por un lado identificar cada una de las asignaturas aprobadas en el primer año, incorporando el número de horas que estas tienen $y$, por otro, revisar que estas asignaturas sean del plan de estudio que el estudiante cursa. Este total de horas aprobadas se contrasta con el total de horas del plan del primer año que el estudiante debió cursar. Para cada estudiante se calcula el avance curricular al primer y al tercer año.

h. Ayuda de arancel. Corresponde a estudiantes que poseen un beneficio asociado al arancel por medio de alguna beca y/o crédito.

i. Participación en programas de apoyo académico. En esta variable se identifica si el estudiante participó en algún programa de este tipo. Para efectos de esta investigación se analizó la participación de los estudiantes en el Programa Rüpü (o también llamada Participación en Rüpü). Si bien los programas de apoyo se concentran en los estudiantes de primer año, se espera que el hecho de recibir apoyo académico también influya en el comportamiento académico del estudiante en la trayectoria universitaria posterior. Para considerar si el estudiante participó o no en un programa de apoyo solo se analiza la aprobación de, al menos, un taller (cada taller consta de 12 horas cronológicas). 
64 FACTORES ASOCIADOS A LA DESERCIÓN/RETENCIÓN DE LOS ESTUDIANTES MAPUCHE DE LA UNIVERSIDAD DE LA FRONTERA E INCIDENCIA DE LOS PROGRAMAS DE APOYO ACADÉMICO - S. Navarrete, R. Candia, R. Puchi

\subsection{Análisis de datos}

Para identificar las variables que influyen en la permanencia de estudiantes en la universidad, tanto en primer como en tercer año, se utilizó la estimación de un modelo de regresión logística por la máxima verosimilitud, el que se basa en el utilizado por el Centro de Estudios Mineduc (Mineduc, 2012). El ajuste del modelo se realizó considerando la segmentación entre la ascendencia declarada de los estudiantes, de modo que tenemos estudiantes mapuche y no mapuche y un análisis de variables en bloques para observar el comportamiento de los grupos de variables respecto de la permanencia en la universidad, de forma tal que tenemos un primer bloque caracterizado por incluir las variables propias del ambiente del estudiante (variables sociodemográficas), seguido por el de las características asociadas al entorno y rendimiento académico previo (variables académicas), la vocación y los beneficios de arancel (becas y/o crédito universitario) en un tercer bloque y, finalmente, los dos últimos bloques con variables asociadas al rendimiento académico y a la participación en actividades de apoyo académico (Programa Rüpü).

Otro de los puntos respecto del análisis fue evaluar el comportamiento del avance curricular en función de la participación en el Programa Rüpü y, además, constatar la presencia de otras variables independientes, como los factores sociodemográficos, académicos y la preferencia de postulación a la carrera. El modelo seleccionado es de regresión lineal e incluye las variables más significativas en algunos de los grupos, tanto de estudiantes mapuche o no mapuche.

Por último, si bien se tuvo el comportamiento de la participación en el Programa Rüpü en presencia de las demás variables asociadas al estudiante y al rendimiento académico alcanzado, en esta subsección se abordó el porcentaje de estudiantes que permanecían en la institución, pertenecientes o bien que habían pasado por este programa (según la definición de participación dada), en comparación con los estudiantes mapuche de las mismas facultades pero que no habían tenido apoyo académico de dicho programa. 


\subsection{Resultados}

\subsubsection{Antecedentes descriptivos}

Un dato destacable es el hecho de que los estudiantes mapuche que participaron en el Programa Rüpü presentaban condiciones desfavorables en el ingreso a la universidad respecto de los estudiantes mapuche que no participaban en él. Recordemos que el estudio consideró las facultades que presentaban la mayor proporción de estudiantes participantes, es decir, Ingeniería y Ciencias, Ciencias Agropecuarias y Forestales y de Educación, Ciencias Sociales y Humanidades. Estos resultados, transversal y longitudinal, respectivamente, se muestran en las Tablas 3 y 4.

Por otra parte, si bien los estudiantes mapuche (y dentro de este grupo los participantes en el Programa Rüpü) presentan condiciones de entrada que los hacen académicamente desfavorables, estas diferencias tienden a equipararse para los estudiantes Rüpü en el rendimiento académico universitario. Estos resultados se aprecian en la tabla siguiente.

Tabla 5: Rendimiento académico por ascendencia mapuche declarada. Datos al primer y tercer año

\begin{tabular}{|l|c|c|c|c|c|c|}
\hline \multirow{2}{*}{ Tipo de participante } & \multicolumn{3}{|c|}{ Primer año } & \multicolumn{3}{|c|}{ Tercer año } \\
\cline { 2 - 7 } & Cantidad & PPS & Avance curricular & Cantidad & PPS & Avance curricular \\
\hline Estudiantes no mapuche \\
\hline No participa \\
\hline Estudiantes mapuche & 4608 & 4,37 & $66 \%$ & 3767 & 4,61 & $76 \%$ \\
\hline No participa & 1204 & 4,27 & $62 \%$ & 956 & 4,56 & $74 \%$ \\
\hline Rüpü & 130 & 4,46 & $63 \%$ & 113 & 4,65 & $73 \%$ \\
\hline
\end{tabular}

A continuación se presenta un estudio descriptivo de las variables independientes en la investigación medidas al primer año y de la cantidad de estudiantes al primer y tercer año, considerando la segmentación por ascendencia mapuche declarada. 
66 FACTORES ASOCIADOS A LA DESERCIÓN/RETENCIÓN DE LOS ESTUDIANTES MAPUCHE DE LA UNIVERSIDAD DE LA FRONTERA E INCIDENCIA DE LOS PROGRAMAS DE APOYO ACADÉMICO - S. Navarrete, R. Candia, R. Puchi

Tabla 6: Descripción de las variables en estudio. Deserción/retención al primer año

\begin{tabular}{|c|c|c|c|c|c|c|c|c|}
\hline \multirow{2}{*}{\multicolumn{2}{|c|}{ Variables }} & \multicolumn{3}{|c|}{ Deserción } & \multicolumn{3}{|c|}{ Retención } & \multirow[b]{2}{*}{$\begin{array}{l}\text { Total } \\
\text { general }\end{array}$} \\
\hline & & Mapuche & $\begin{array}{c}\text { No } \\
\text { mapuche }\end{array}$ & $\begin{array}{c}\text { No } \\
\text { declarada }\end{array}$ & Mapuche & \begin{tabular}{|c|} 
No \\
mapuche
\end{tabular} & $\begin{array}{c}\text { No } \\
\text { declarada }\end{array}$ & \\
\hline \multicolumn{9}{|c|}{ Régimen educativo colegio } \\
\hline \multicolumn{2}{|c|}{ Municipalizado } & 134 & 343 & 49 & 582 & 1.421 & 217 & 2.746 \\
\hline \multicolumn{2}{|c|}{ Particular subvencionado } & 129 & 465 & 74 & 559 & 2.230 & 380 & 3.837 \\
\hline \multicolumn{2}{|c|}{ Particular pagado } & 13 & 56 & 6 & 6 & 224 & 30 & 335 \\
\hline \multicolumn{9}{|l|}{ Tipo de colegio } \\
\hline \multicolumn{2}{|l|}{ Técnico profesional } & 77 & 113 & 15 & 213 & 426 & 70 & 914 \\
\hline \multicolumn{2}{|l|}{ Científico-Humanista } & 199 & 751 & 114 & 934 & 3.449 & 557 & 6.004 \\
\hline \multirow{2}{*}{ Sexo } & Masculino & 177 & 561 & 79 & 710 & 2.462 & 394 & 4.383 \\
\hline & Femenino & 105 & 322 & 58 & 450 & 1.477 & 247 & 2.659 \\
\hline \multicolumn{9}{|l|}{ Tipo de localidad } \\
\hline \multicolumn{2}{|l|}{ Ciudad de Temuco } & 102 & 432 & 27 & 429 & 1.902 & 243 & 3.135 \\
\hline \multicolumn{2}{|l|}{ Localidad rural } & 99 & 116 & 5 & 361 & 515 & 72 & 1.168 \\
\hline \multicolumn{2}{|l|}{ Otra ciudad (urbano) } & 64 & 265 & 21 & 293 & 1.194 & 139 & 1.976 \\
\hline \multirow{2}{*}{ Nivel socioeconómico } & Alto & 211 & 562 & 67 & 930 & 2.449 & 384 & 4.603 \\
\hline & 0 & 71 & 321 & 70 & 230 & 1.490 & 257 & 2.439 \\
\hline \multicolumn{9}{|c|}{ Vocación por la carrera de ingreso } \\
\hline \multicolumn{2}{|l|}{ Primera preferencia } & 129 & 460 & 59 & 705 & 2.482 & 359 & 4.194 \\
\hline \multicolumn{2}{|c|}{ No es primera preferencia } & 133 & 363 & 62 & 372 & 1.191 & 221 & 2.342 \\
\hline \multirow[t]{2}{*}{ Rendimiento previo } & \begin{tabular}{|l|} 
Promedio notas \\
enseñanza media
\end{tabular} & 5,78 & 5,77 & 5,78 & 5,87 & 5,87 & 5,86 & 5,85 \\
\hline & Promedio PSU & 563,0 & 573,8 & 561,1 & 575,6 & 586,7 & 587,3 & 581,9 \\
\hline Posee crédito de arar & acel (primer año) & & & & & & & \\
\hline Posee & & 186 & 521 & 67 & 939 & 2.853 & 490 & 5.056 \\
\hline No posee & & 96 & 362 & 70 & 221 & 1.086 & 151 & 1.986 \\
\hline Posee beca arancel ( & orimer año) & & & & & & & \\
\hline Posee & & 103 & 284 & 18 & 600 & 1.648 & 246 & 2.899 \\
\hline No posee & & 179 & 599 & 119 & 560 & 2.291 & 395 & 4.143 \\
\hline Participación en apo & yo académico & & & & & & & \\
\hline Estudiante Rüpü & & 19 & - & - & 123 & - & - & 142 \\
\hline Rendimiento académ & ico universidad (pr & imer año) & & & & & & \\
\hline Avance curricular & & $37 \%$ & $36 \%$ & $43 \%$ & $69 \%$ & $73 \%$ & $75 \%$ & $66 \%$ \\
\hline Promedio ponderadc & semestral & 3,21 & 3,27 & 3,23 & 4,49 & 4,55 & 4,61 & 4,36 \\
\hline Cantidad total de est & udiantes por año & seguimien & & & & & & \\
\hline Al primer año & & 282 & 883 & 137 & 1.160 & 3.939 & 641 & 7.042 \\
\hline Al tercer año & & 538 & 1.749 & 185 & 622 & 2.190 & 456 & 5.740 \\
\hline
\end{tabular}




\subsection{Variables asociadas a la deserción académica en estudiantes de la UFRO. Comparación entre estudiantes mapuche y no mapuche}

A partir del modelo de regresión logística ajustado se tiene que para el primer bloque, es decir, el de variables sociodemográficas, se presentan resultados significativos solo para los estudiantes mapuche. De forma particular podemos decir que la condición de ruralidad se asocia inversamente con la probabilidad de permanecer y que el nivel socioeconómico es un factor protector para la permanencia de los estudiantes en la universidad.

Sin embargo, el nivel socioeconómico deja de tener efecto significativo sobre la permanencia solo cuando ingresan las variables de rendimiento académico, indicadores que se mantienen al adicionar los números y relaciones con la participación de los estudiantes en el Programa Rüpü.

Por otra parte, al considerar las variables académicas para los estudiantes mapuche se tiene que el régimen educativo de su establecimiento de egreso de enseñanza media, tanto en el caso de los colegios municipalizados como en el de los colegios particulares subvencionados, se relacionan directamente con la probabilidad de permanecer en la universidad, en comparación con el régimen educativo particular pagado. En cambio para los estudiantes no mapuche esta misma variable no tiene efecto significativo en el modelo. Además, en los dos grupos (mapuche y no mapuche) esta situación se mantiene para los nuevos bloques.

En los bloques dos y tres para estudiantes mapuche, el egreso de un establecimiento científico-humanista y el promedio obtenido en la PSU tienen relación directa con la probabilidad de permanecer en la universidad, aunque este efecto parece no permanecer si se incluye el rendimiento académico en el primer año. Para los estudiantes no mapuche solo el promedio obtenido en la PSU produce efectos directos y significativos sobre la probabilidad de permanecer, mientras que al ingresar a la universidad el rendimiento académico aparece como significativo respecto del efecto del promedio de notas de enseñanza media, pero lo hace como relación inversa. 
Otros factores por considerar son que para los estudiantes mapuche la vocación, medida por el número de preferencia, tiene efectos significativos sobre la permanencia en la universidad en presencia de variables académicas previas y sociodemográficas. Sin embargo, este efecto desaparece al ingresar las variables de rendimiento académico universitario (al primer año). Por su parte, para los estudiantes no mapuche, la vocación y el poseer beneficios de arancel constituyen factores favorables para la permanencia en la universidad.

Por su parte, el avance curricular al primer año es un factor que correlaciona directamente con la probabilidad de permanecer en la universidad para ambos grupos de estudiantes. Este resultado complementa el encontrado por Rodríguez y Ruiz (2011), el que establece que el avance curricular es buen predictor del rendimiento académico.

Al primer año, la participación en el Programa Rüpü no produjo efectos significativos sobre la permanencia en la universidad por parte de los estudiantes, lo que representa un resultado por destacar, pues si bien no existe un efecto significativo (positivo) del programa en la retención, también hay que recordar que estos estudiantes son desfavorecidos en condiciones académicas de entrada.

Tabla 7: Estimación de parámetros del modelo de regresión logístico por bloques para la permanencia de estudiantes en la universidad al primer año

\begin{tabular}{|c|c|c|c|c|c|c|c|c|c|}
\hline \multirow{3}{*}{ Variables } & \multicolumn{5}{|c|}{ Estudiantes mapuche } & \multicolumn{4}{|c|}{ Estudiantes no mapuche } \\
\hline & \multicolumn{5}{|c|}{ Modelos } & \multicolumn{4}{|c|}{ Modelos } \\
\hline & 1 & 2 & 3 & 4 & 5 & 1 & 2 & 3 & 4 \\
\hline Constante & $1,25^{* * *}$ & $-6,33 * *$ & $-5,08^{*}$ & $-7,72 * *$ & $-7,79 * *$ & $1,69 * * *$ & $-2,20+$ & $-1,98+$ & $-3,44 *$ \\
\hline \multicolumn{10}{|c|}{ Variables sociodemográficas } \\
\hline Sexo: Mujer & 0,036 & 0,098 & 0,154 & $-0,407$ & $-0,385$ & 0,065 & 0,039 & 0,087 & $-0,382 *$ \\
\hline Localidad 1: Temuco & 0,056 & 0,224 & 0,286 & 0,282 & 0,283 & $-0,023$ & $-0,002$ & 0,021 & $-0,154$ \\
\hline Localidad 2: Rural & $-0,481+$ & $-0,345$ & $-0,326$ & $-0,289$ & $-0,267$ & 0,07 & 0,128 & 0,115 & 0,059 \\
\hline NSE: Bajo & $0,514 *$ & $0,501+$ & $0,613^{*}$ & 0,453 & 0,477 & $-0,109$ & $-0,065$ & $-0,191$ & $-0,227$ \\
\hline \multicolumn{10}{|l|}{ Variables académicas } \\
\hline $\begin{array}{l}\text { Régimen educacional l: } \\
\text { Municipal }\end{array}$ & & $2,64 * * *$ & $2,589 * *$ & $3,06 * * *$ & $3,092 * * *$ & & 0,232 & 0,064 & 0,052 \\
\hline $\begin{array}{l}\text { Régimen educacional 2: } \\
\text { P. Subvencionado }\end{array}$ & & $2,63 * * *$ & $2,65 * * *$ & $3,081 * * *$ & $\mid 3,099 * * *$ & & 0,277 & 0,113 & $-0,09$ \\
\hline $\begin{array}{l}\text { Tipo de colegio: } \\
\text { Científico Humanista }\end{array}$ & & $0,417+$ & $0,467+$ & 0,362 & 0,349 & & 0,096 & 0,13 & 0,048 \\
\hline
\end{tabular}




\begin{tabular}{|c|c|c|c|c|c|c|c|c|c|}
\hline $\begin{array}{l}\text { Promedio notas } \\
\text { enseñanza media }\end{array}$ & & 0,202 & 0,083 & $-0,525$ & $-0,534$ & & 0,265 & 0,196 & $-0,669 * *$ \\
\hline Promedio PSU & & $0,006^{*}$ & $0,005+$ & 0,001 & 0,002 & & $0,003^{*}$ & $0,003^{*}$ & $-0,001$ \\
\hline \multicolumn{10}{|c|}{ Vocación y beneficios de arancel } \\
\hline Primera preferencia: Sí & & & $0,608^{* *}$ & 0,319 & 0,323 & & & $0,39 * *$ & $0,565^{* * *}$ \\
\hline Ayuda arancel: Sí & & & $-0,263$ & $-0,212$ & $-0,208$ & & & $0,452^{*}$ & $0,758^{* *}$ \\
\hline \multicolumn{10}{|c|}{ Rendimiento académico primer año } \\
\hline $\begin{array}{l}\text { Promedio ponderado } \\
\text { semestral }\end{array}$ & & & & 0,131 & 0,127 & & & & $0,234 *$ \\
\hline LN Avance curricular & & & & $1,996 * * *$ & $2,008^{* * *}$ & & & & $2,103^{* * *}$ \\
\hline \multicolumn{10}{|l|}{ Apoyo académico } \\
\hline Participación Rüpü & & & & & $-0,275$ & & & & \\
\hline \multicolumn{10}{|l|}{ Indicadores del modelo } \\
\hline $\mathrm{N}$ & \multicolumn{5}{|c|}{661} & \multicolumn{4}{|c|}{2276} \\
\hline$-2 \log$ verosimilitud & 617,5 & 596,1 & 588,1 & 430,5 & 430,0 & 2016,1 & 2002,9 & 1988,1 & 1391,9 \\
\hline R cuadrado & 0,022 & 0,073 & 0,073 & 0,419 & 0,419 & 0,001 & 0,011 & 0,022 & 0,409 \\
\hline
\end{tabular}

Fuente: Elaboración propia.

Por su parte, para el tercer año, en el modelo completo, se aprecia que tanto para el grupo de estudiantes mapuche como para quienes declaran no pertenecer a este grupo étnico las variables que tienen influencia en la permanencia en la universidad son los factores académicos por sobre todos los demás.

Además, e igual que en primer año, participar en el Programa Rüpü no tiene efecto sobre la permanencia en la universidad, ni tampoco produce cambios en las estimaciones de los parámetros asociados a las demás variables.

Tabla 8: Estimación de parámetros del modelo de regresión logístico por bloques para la permanencia de estudiantes en la universidad al tercer año

\begin{tabular}{|c|c|c|c|c|c|c|c|c|c|}
\hline \multirow{3}{*}{ Variables } & \multicolumn{5}{|c|}{ Estudiantes mapuche } & \multicolumn{4}{|c|}{ Estudiantes no mapuche } \\
\hline & \multicolumn{5}{|c|}{ Modelos } & \multicolumn{4}{|c|}{ Modelos } \\
\hline & 1 & 2 & 3 & 4 & 5 & 1 & 2 & 3 & 4 \\
\hline Constante & $2,036 * * *$ & 10,694 & 10,607 & 6,094 & 6,132 & $2,2 * * *$ & $-6,91^{* * *}$ & $-6,81^{* * *}$ & $-12,6 * * *$ \\
\hline \multicolumn{10}{|c|}{ Variables sociodemográficas } \\
\hline Sexo: Mujer & $0,76^{* * *}$ & $0,605^{*}$ & $0,571^{*}$ & $-0,203$ & $-0,188$ & $0,87^{* * *}$ & $0,695 * * *$ & $0,684 * * *$ & 0,026 \\
\hline Localidad 1: Temuco & 0,004 & 0,15 & 0,146 & $-0,211$ & $-0,222$ & $-0,081$ & 0,085 & 0,083 & $-0,109$ \\
\hline Localidad 2: Rural & $-0,342$ & $-0,157$ & $-0,162$ & $-0,278$ & $-0,272$ & $-0,361^{*}$ & $-0,295$ & $-0,287$ & $-0,265$ \\
\hline NSE: Bajo & $-0,203$ & 0,098 & $-0,032$ & $-0,355$ & $-0,353$ & $-0,246+$ & $-0,165$ & $-0,145$ & $-0,108$ \\
\hline \multicolumn{10}{|l|}{ Variables académicas } \\
\hline $\begin{array}{l}\text { Régimen educacional l: } \\
\text { Municipal }\end{array}$ & & 0,308 & 0,282 & $-0,046$ & $-0,063$ & & $-0,077$ & $-0,088$ & $-0,058$ \\
\hline
\end{tabular}



MAPUCHE DE LA UNIVERSIDAD DE LA FRONTERA E INCIDENCIA DE LOS PROGRAMAS DE APOYO ACADÉMICO - S. Navarrete, R. Candia, R. Puchi

\begin{tabular}{|c|c|c|c|c|c|c|c|c|c|}
\hline $\begin{array}{l}\text { Régimen educacional 2: } \\
\text { P. Subvencionado. }\end{array}$ & & $-18,531$ & $-18,636$ & $-17,222$ & $-17,214$ & & 0,259 & 0,284 & 0,357 \\
\hline $\begin{array}{l}\text { Tipo de colegio: } \\
\text { Científico Humanista }\end{array}$ & & $-18,566$ & $-18,668$ & $-17,402$ & $-17,402$ & & 0,111 & 0,135 & 0,172 \\
\hline $\begin{array}{l}\text { Promedio notas } \\
\text { enseñanza media }\end{array}$ & & $0,744^{*}$ & $0,735^{*}$ & $-0,353$ & $-0,367$ & & $1,013 * * *$ & $1,018^{* * *}$ & 0,144 \\
\hline Promedio PSU & & $0,008 * *$ & $0,009 * *$ & 0,003 & 0,003 & & $0,005 * * *$ & $0,005^{* * *}$ & 0,001 \\
\hline \multicolumn{10}{|c|}{ Vocación y beneficios de arancel } \\
\hline Primera preferencia: Sí & & & $-0,27$ & $-0,111$ & $-0,109$ & & & $-0,091$ & 0,139 \\
\hline Ayuda arancel: Sí & & & 0,459 & 0,12 & 0,137 & & & $-0,099$ & $-0,041$ \\
\hline \multicolumn{10}{|c|}{ Rendimiento académico tercer año } \\
\hline $\begin{array}{l}\text { Promedio ponderado } \\
\text { semestral }\end{array}$ & & & & $1,791^{* * *}$ & $1,797^{* * *}$ & & & & $1,32 * * *$ \\
\hline LN Avance curricular & & & & $1,558^{* * * *}$ & $1,549 * *$ & & & & $1,91^{* * *}$ \\
\hline \multicolumn{10}{|l|}{ Apoyo académico } \\
\hline Participación Rüpü & & & & & $-0,194$ & & & & \\
\hline \multicolumn{10}{|l|}{ Indicadores del modelo } \\
\hline $\mathrm{N}$ & \multicolumn{5}{|c|}{798} & \multicolumn{4}{|c|}{3419} \\
\hline$-2 \log$ verosimilitud & 541,5 & 510,8 & 508,7 & 333,5 & 333,3 & 1972,5 & 1883,5 & 1882,9 & 1312,6 \\
\hline R cuadrado & 0,031 & 0,105 & 0,11 & 0,482 & 0,483 & 0,036 & 0,093 & 0,093 & 0,422 \\
\hline
\end{tabular}

Fuente: Elaboración propia.

\subsection{Retención en estudiantes mapuche Rüpü}

La estimación de la retención se realiza al primer y tercer año. En ambas mediciones se tiene que el porcentaje de estudiantes mapuche que ha participado en el Programa Rüpü alcanza mejores indicadores de retención respecto de aquellos estudiantes mapuche que no han participado. Sin embargo, estas diferencias no alcanzan a ser estadísticamente significativas.

Además, considerando la participación en Rüpü como un factor explicativo de la permanencia en la universidad y en presencia de las demás variables (ver Tablas 1 y 2), se obtuvo que este factor no está significativamente relacionado con la permanencia respecto de los estudiantes mapuche que no participan. 
Tabla 9: Permanencia en la universidad de estudiantes mapuche, comparación entre tipo de participante al primer y tercer año

\begin{tabular}{|l|c|c|c|c|c|c|}
\hline \multirow{2}{*}{$\begin{array}{l}\text { Estudiantes } \\
\text { mapuche }\end{array}$} & \multicolumn{3}{|c|}{ Primer año universidad* } & \multicolumn{3}{c|}{ Tercer año universidad** } \\
\cline { 2 - 7 } & Cantidad & Retención & Desviación típ. & Cantidad & Retención & Desviación típ. \\
\hline Rüpü & 155 & $87 \%$ & $34 \%$ & 116 & $72 \%$ & $45 \%$ \\
\hline No Rüpü & 1.893 & $83 \%$ & $38 \%$ & 1.232 & $73 \%$ & $44 \%$ \\
\hline & \multicolumn{3}{|c|}{$\left({ }^{*}\right)$ p-value $=0.116$} & \multicolumn{3}{c|}{$(* *)$ p-value $=0.823$} \\
\hline
\end{tabular}

2.6. Asociación entre el apoyo académico y el nivel de avance curricular de los estudiantes mapuche de la Universidad de La Frontera

En cuanto a los resultados se tiene aquí que los estudiantes mapuche pertenecientes o que han pertenecido al Programa Rüpü presentan un porcentaje de avance curricular levemente superior en comparación con aquellos estudiantes mapuche que no participan en dicha iniciativa, tanto al primer año $(63,7 \%$ y $62,5 \%$, respectivamente) como al tercero $(74,0 \%$ y $73,5 \%$, respectivamente). Sin embargo, estas diferencias no son estadísticamente significativas.

Si se consideran otras variables (como las asociadas a factores sociodemográficos, las académicas y la vocación), al primer año la participación en Rüpü no tiene un efecto significativo, en tanto que las variables que explican el avance curricular tienen que ver principalmente con características académicas y la diferencia radicaría en la preferencia por la carrera, la que es significativa para los estudiantes mapuche.

Por su parte, al tercer año el rendimiento previo (primer año de universidad) es el principal factor, haciendo aumentar la capacidad explicativa del modelo respecto del anterior. El nivel socioeconómico bajo implica una relación positiva con el avance curricular y la participación en Rüpü es negativa y significativa, llegando al 10\%. 
Tabla 10: Variables explicativas del avance curricular, al primer y tercer año, según ascendencia mapuche declarada y efecto de participación en Programa Rüpü

\begin{tabular}{|c|c|c|c|c|}
\hline \multirow{2}{*}{ Variables } & \multicolumn{2}{|c|}{ Primer año } & \multicolumn{2}{|c|}{ Tercer año } \\
\hline & Mapuche & No mapuche & Mapuche & No mapuche \\
\hline Constante & $-74,538 * * *$ & $-84,413^{* * *}$ & $-40,154 * *$ & $-33,246 * * *$ \\
\hline Sexo: Mujer & $11,302^{* * *}$ & $8,294 * * *$ & 1,62 & $1,779 *$ \\
\hline Nivel socioeconómico: Bajo & 3,72 & $-1,148$ & $4,307^{*}$ & 0,111 \\
\hline Promedio notas enseñanza media & $10,136^{* * *}$ & $13,926^{* * *}$ & $-1,521$ & $-0,591$ \\
\hline Promedio PSU & $0,117^{* * *}$ & $0,117^{* * *}$ & $0,03+$ & $-0,002$ \\
\hline Primera preferencia: Sí & $5,937^{* *}$ & 0,049 & $-2,146$ & $-2,168 * *$ \\
\hline PPS primer año & & & $22,12 * * *$ & $24,236^{* * *}$ \\
\hline Participante Rüpü & $-0,353$ & & $-4,482+$ & \\
\hline \multicolumn{5}{|l|}{ Indicadores del modelo } \\
\hline $\mathrm{N}$ & 698 & 2615 & 526 & 2186 \\
\hline R cuadrado & 0,103 & 0,107 & 0,404 & 0,486 \\
\hline
\end{tabular}

Fuente: Elaboración propia.

\section{Conclusiones}

Los principales hallazgos se encontraron en el grupo de variables de rendimiento académico, ya que tanto los estudiantes mapuche como los no mapuche tienen menos probabilidades de desertar en la medida en que aumenta el nivel de avance curricular y, al igual que en el estudio de Saldaña y Barriga (2010), las variables de desempeño académico se vuelven más importantes para las probabilidades de permanecer que las variables previas al ingreso a la universidad.

Por otra parte, las notas de enseñanza media constituyen una variable que se relaciona con las probabilidades de deserción en el grupo no mapuche, aunque esta pierde su peso explicativo al ingresar el grupo de variables de rendimiento académico.

Como lo plantean los modelos empíricos revisados, el establecimiento de procedencia y el quintil socioeconómico son variables importantes para explicar la deserción. Efectivamente, en el presente estudio estas variables surgen como relevantes solo en el grupo de estudiantes mapuche, sin embargo, ello ocurre en el sentido inverso de lo esperado: aquellos estudiantes que provienen de establecimientos municipalizados y particulares subvencionados 
tienen más probabilidades de permanecer en la educación superior; si se considera que los estudiantes que provienen de estos establecimientos son también más vulnerables, significa que a mayor vulnerabilidad de los estudiantes mapuche, menores son las posibilidades de desertar.

Canales y De los Ríos (2009) plantean que los grupos de estudiantes más vulnerables realizan un esfuerzo mayor por permanecer en la universidad y hacen uso de una serie de recursos disponibles tanto a nivel personal y familiar como institucionalmente, lo que los lleva a avanzar en su carrera universitaria, debido a la valoración del logro de ingreso que han realizado.

Por lo tanto, los estudiantes mapuche son más persistentes y realizan una mayor valoración de la educación superior, elementos que les permiten permanecer y tener menores riesgos de deserción a pesar de su alta vulnerabilidad, como concluyó González (2007). De igual forma este fenómeno podría estar relacionado con variables psicológicas como la resiliencia, que como plantea Masten (1994), hace que los estudiantes con esta condición posean una visión proactiva y consciente de las barreras, dificultades y oportunidades que el sistema les ofrece.

También dicho fenómeno se puede explicar por las conclusiones de Canales y De los Ríos (2009), quienes plantean que los grupos vulnerables hacen uso efectivo de la mayoría de los soportes y recursos para hacer frente a las dificultades que enfrentan en la educación superior, lo que podría indicar que los estudiantes mapuche, a pesar que no estar en igualdad de condiciones de ingreso y de conocimientos iniciales, despliegan una serie de «otras acciones» para mantenerse en la universidad, activando todos los mecanismos administrativos que otorga su régimen de estudio de pregrado para permanecer en su carrera.

Estos resultados sugieren que la permanencia de los estudiantes mapuche en la universidad al primer año está marcada principalmente por variables asociadas al sujeto y por las «acciones administrativas» que el estudiante realiza para poder permanecer en la educación 
superior. Ello implica que este ha sido históricamente marginado, discriminado como pueblo y por las desigualdades de acceso a una educación de calidad, logra sobreponerse a todas esas barreras, incluso a aquellas más duras como la desigualdad de conocimientos previos y las inconsistencias en torno al modelo de aprendizaje que vivió.

El análisis del modelo al tercer año muestra que las únicas variables significativas en cuanto a la deserción es el promedio de notas ponderado, es decir, que los estudiantes que poseen mejores notas tienen menos probabilidades de desertar y esto es indistintamente si pertenecen o no al grupo mapuche. Estos datos llevan a plantearnos que efectivamente las variables que explican la deserción al primer año (sociodemográficas y académicas previas) pierden valor transcurridos tres años de vida universitaria, lo que significa que a pesar de que los estudiantes mapuche poseen mayores barreras de ingreso a la educación superior, provienen en su mayoría de establecimientos municipales y particulares subvencionados y que además, ingresan a esta con puntajes de PSU más bajos que el grupo no mapuche, tendiendo a homologar sus características al grupo no mapuche y a depender mayoritariamente de su desempeño académico para permanecer en la universidad.

Como vemos, el estudiante mapuche debe enfrentar mayores desafíos y obstáculos en su carrera educativa y en todos sus niveles, dejando de manifiesto las grandes desigualdades que existen en términos de calidad educativa a nivel regional y, en el caso de la Región de La Araucanía, en aquellos grupos social e históricamente marginados como son los estudiantes pertenecientes al pueblo mapuche.

Otro de los objetivos de esta investigación decía relación con determinar si existía una asociación entre los programas de apoyo académico y el avance curricular de los estudiantes mapuche de la UFRO. Al respecto, si se observan los datos descriptivos y los antecedentes generales de la población estudiantil mapuche, se puede apreciar que estos poseen mayores debilidades académicas de ingreso, lo que en cierta medida los vuelve más vulnerables a la deserción, indistintamente de su condición socioeconómica. Sin embargo, el grupo que participa en los programas de apoyo académico presenta 
mayores desventajas de ingreso, las que se reflejan en menores puntajes PSU que los estudiantes mapuche que no participan de estos programas de apoyo académico. A pesar de que los grupos no difieren significativamente, los estudiantes que participan presentan un mejor avance curricular que los de los estudiantes mapuche que no participan, lo que implica que los alumnos logran superar las desventajas de ingreso e igualar el avance curricular de los estudiantes que no requieren participar de estos programas de apoyo.

El último objetivo fue verificar si la participación de estos estudiantes contribuye a la retención de los mismos en el primer y tercer año. En este sentido, como se observa en los resultados, los estudiantes que participan en el programa tienen indicadores de retención similares a los de los estudiantes mapuche que no participan del mismo. Si se considera que los estudiantes mapuche que participan en el programa son aquellos que poseen mayores desigualdades de ingreso, indistintamente de sus características socioeconómicas, es altamente relevante la participación en este programa, ya que de este modo logran adquirir las competencias necesarias para homologar sus niveles de retención.

Como plantea Abatte (2008), los estudiantes no tradicionales tienden a mostrar indicadores de titulación más deficientes que aquellos que no pertenecen a grupos no tradicionales. Del mismo modo esta autora explica que parte de este resultado tiene que ver con las dificultades lingüísticas que no son abordadas de forma exitosa por los docentes en sus clases, agregando así nuevas barreras en el proceso de enseñanza-aprendizaje. Estas conclusiones adquieren un sentido adicional cuando se observa que los estudiantes que participan en el Programa Rüpü, a pesar de ingresar con mayores deficiencias que los mapuche que no participan, logran homologar su rendimiento académico, lo que podría explicarse por el modelo pedagógico que utiliza dicha iniciativa (González, 2007), el que se basa, precisamente, en un paradigma de aprendizaje sociocultural que promueve la generación del conocimiento cooperativo y se adapta a la forma tradicional de transmisión oral de conocimiento de la cultura mapuche (Bello et al., 1997). De esta forma, los estudiantes que participan en el programa logran identificarse con la universidad en 
un espacio que es más consistente con su cosmovisión y así generan un sentido de pertenencia, integración y compromiso, elementos que según Pascarella y Chapman (1983) tienen un efecto positivo en la permanencia de los estudiantes en la educación superior.

Asimismo, la homologación de los resultados de retención de los estudiantes que participan del Programa Rüpü podría obedecer a la inclusión en espacios académicos culturalmente pertinentes, la que le facilita al estudiante compartir su experiencia previa y vincularse con los nuevos conocimientos adquiridos en un ambiente de colaboración con otros compañeros de cursos superiores y docentes comprometidos con la cultura mapuche. De esta forma el estudiante logra un mayor empoderamiento y activa las redes sociales necesarias para desenvolverse de forma adecuada durante su paso por la universidad.

\section{Referencias bibliográficas}

Abbate Vaughn, J., (2008) «Admisión, apoyo y retención de estudiantes no tradicionales en carreras universitarias», en REICE: Revista Electrónica Iberoamericana sobre Calidad, Eficacia y Cambio en Educación. Vol. 6, $\mathrm{N}^{\circ}$ 3, 2008, pp. 7-35.

Acuña Véliz, C., (2012) Acceso y deserción en la educación superior: caso aplicado a Chile. Tesis de Magíster. Santiago, Facultad de Ciencias Físicas y Matemáticas, Universidad de Chile. [En línea], disponible en http:// www.tesis.uchile.cl/handle/2250/112062 [recuperado el 24 de mayo de 2013].

Assef, C. y S. Becerra, (2010) «La universidad frente a la diversidad estudiantil: Universidad Bernardo O’Higgins, el caso de una universidad privada inclusiva» [En línea], disponible en: http://www.ciie2010.cl/docs/doc/ sesiones/251_CAssef_Universidad_diversidad_UBioBio.pdf [Extraído el 1 de agosto de 2013].

Barrios, M.A., (2011) Deserción y financiamiento en las universidades chilenas. Tesis de maestría no publicada. Santiago, Pontificia Universidad Católica de Chile, Chile.

Barrios, A., (2013) «Deserción universitaria en Chile: incidencia del financiamiento y otros factores asociados» en Revistacis [En línea], disponible en: http://www.techo.org/wp-content/uploads/2013/02/ barrios.pdf [Recuperado el 01 de agosto de 2013]. 
Barrios, A.; Meneses, F.; Paredes, R. y M. Silva, (2011) Financial Aid and University Attrition in Chile. Documento de trabajo. Santiago. Departamento de Ingeniería Industrial, Pontificia Universidad Católica de Chile.

Blanco, C. y F. Meneses, (2011) «Estudiantes indígenas y educación superior en Chile: acceso y beneficio», en Inclusión Social, Interculturalidad y Equidad en Educación Superior. Seminario Internacional Inclusión Social y Equidad en la Educación Superior. $2^{\circ}$ Encuentro Interuniversitario de Educación Superior, Temuco, desde el 29 de septiembre al 1 de octubre de 2010, Fundación Equitas, Chile.

Braxton, J.M.; Milem, J.F., y A. S. Sullivan, (2000) «The Influence of Active Learning on the College Student Departure Process: Toward a Revision of Tinto's Theory», en Journal of Higher Education. Vol. 71, No 5 , septiembre - octubre 2000, pp. 569-590.

Bello, A.; Willson, A.; González, S. y P. Marimán, (1997) Pueblos indígenas, educación y desarrollo. Temuco, Centro de estudios para el desarrollo de la Mujer. Instituto de Estudios Indígenas, Universidad de La Frontera.

Canales, A. y D. De los Ríos, (2009) «Retención de estudiantes vulnerables en la educación universitaria», en Calidad en la Educación. № 30, Primer semestre 2009, pp. 49-83.

Catterall, J.S., (1998) «Risk and resilience in student transitions to high school», en American Journal of Education. Vol. 106, No 2, pp. 302-333.

Centro de Microdatos, Universidad de Chile (2008). Informe final: "Estudios sobre las causas de la deserción universitaria". Departamento de Economía. Universidad de Chile.

Díaz, C., (2008) «Modelo conceptual para la deserción estudiantil universitaria chilena», en Estudios pedagógicos. Vol. 34, No 2, pp. 65-86.

Donoso, S. y V. Cancino, (2007) «Caracterización socioeconómica de los estudiantes de educación superior», en Calidad en la Educación. № 26, Primer semestre 2007, pp. 203-244.

Donoso, S.; Donoso, G. y Ó. Arias, (2010) «Iniciativas de retención de estudiantes de educación superior», en Calidad en la Educación. № 33, Segundo semestre 2010, pp. 15-61.

Donoso, S. y E. Schiefelbein, (2007) «Análisis de los modelos explicativos de retención de estudiantes en la universidad: una visión desde la desigualdad social», en Estudios Pedagógicos. Vol. 33, No 1, pp. 7-17.

Eccles, J.; Adler, T.F.; Futerrman, R.; Goff, S.B.; Kaczala, C.M.; Meece, J.L. y C. Midgley, (1983) «Expectancies, Values, and Academic Behaviors», 
en J.T. Spence (ed.), Achievement and Achievement Motives: Psychological and sociological approaches. San Francisco, W.H. Freeman and Co.

Elboj, C.; Valls, R. y M. Fort, (2000) «Comunidades de aprendizaje. Una práctica educativa para la sociedad de la información», en Cultura y Sociedad, Vol. 12, No 1, pp. 129-141.

Ethington, C.A., (1990) «A Psychological Model of Student Persistence», en Research in Higher Education. Vol. 31, No 3, junio 1990, pp. 266-269.

Goldfinch, J. y M. Hughes, (2007) «Skills, Learning Styles and Success of First-Year under Graduates», en Active Learning in Higher Education. Vol. 8, No 3, noviembre 2007, pp. 259-273.

González, M.E., (2006) «Reducir desventajas: acciones afirmativas con estudiantes mapuche en la Universidad de La Frontera», en DíazRomero, P. (ed.), Caminos para la inclusión en la educación superior en Chile. Santiago de Chile, Fundación EQUITAS.

González, M.E., (2007) «Proyecto RÜPÜ: un programa de acción afirmativa para estudiantes mapuche», en Ansión, J. y Tubino, F. (coord), Educar en ciudadanía intercultural: experiencias y retos en la formación de estudiantes universitarios indígenas. Perú, Ministerio de Educación.

Grimes, S. y K. David, (1999) «Underprepared Community College Students: Implications of Attitudinal and Experiential Differences», en Community College Review. Vol. 27, No 2, Otoño 1999, pp. 73-92.

Himmel, E., (2002) Modelos de análisis de la deserción estudiantil en la educación superior. Santiago, Consejo Superior de Educación.

Masten, A.S., (1994) «Resilience in Individual Development: Successful Adaptation Despite Risk and Adversity», en M.C. Wang y G.W., Gordon (eds.), Educational resilience in inner-city America. Hillsdale, Nueva Jersey: Lawrence Erlbaum Associates, Inc.

Ministerio de Educación, (2012) «Deserción en la educación superior en Chile», en Serie Evidencias [En línea] Año 1, No 9, disponible en http:// centroestudios.mineduc.cl [Extraído el 1 de agosto de 2013]

Ministerio de Desarrollo Social, (2009)«Encuesta CASEN 2009». [En línea]. Santiago, disponible en: observatorio.ministeriodesarrollosocial.gob. cl [Extraído el 29 de julio de 2013]

Ministerio de Desarrollo Social, (2011) «Encuesta CASEN 2011, Módulo Educación». [En línea]. Santiago, disponible en observatorio. ministeriodesarrollosocial.gob.cl [Extraído el 29 de julio de 2013]

Navarrete, S. y R. Candia, (2011) «Experiencia de acción afirmativa en educación superior: disminuyendo la brecha con estudiantes mapuche 
de la Universidad de La Frontera», en Revista Educación y Humanidades. Vol. 1, No 2, pp. 32-41.

Organisation for Economic Co-operation and Development, OCDE, (2009) La educación superior en Chile. París, Organización para la Cooperación y el Desarrollo Económico.

Pascarella, E. y D. Chapman, (1983) «A Multi-institutional Path Analytical validation of Tinto's Model of College Withdrawal», en American Education Research Journal. Vol. 20, No 1, pp. 87-102.

Reed-Victor, E. y J.H. Stronge, (2002) «Homeless Students and Resilience: Staff Perspectives on Individual and Environmental Factors», en Journal of Children \& Poverty. Vol. 8, Issue 2, pp. 159-183.

Reyes, J.; Escobar, C.; Duarte, J. y P. Ramírez, (2007). «Una aplicación del modelo de regresión logística en la predicción del rendimiento estudiantil», en Estudios Pedagógicos, Vol. XXXIII, No 2, pp. 101-120.

Rodríguez, M.N. y M.Á. Ruíz, (2011) «Indicadores de rendimiento de estudiantes universitarios: calificaciones versus créditos acumulados», en Revista de Educación. No 355, mayo-agosto 2011, pp. 467-492.

Saldaña, M. y O. Barriga, (2010) «Adaptación del modelo de deserción universitaria de Tinto a la Universidad Católica de la Santísima Concepción, Chile», en Revista de Ciencias Sociales. Vol. 16, No 4, pp. 616-628.

Saiz, J., (2003) Valores en estudiantes universitarios mapuche: una visión transcultural de su contenido, estructura, y jerarquía. Tesis de doctorado. Santiago, Pontificia Universidad Católica de Chile.

Seguel, M., (2005) «Deserción estudiantil del pregrado, PUC». Seminario Internacional sobre Deserción, IESALC/UNESCO, Universidad de Talca, mayo de 2005.

Sistema de Información de la Educación Superior, SIES, (2012) «El aseguramiento de la calidad de la educación superior en Chile». [En línea]. Santiago, disponible en http://www.divesup.cl [Recuperado el 17 de mayo de 2013].

Tillman, C.A., (2002) «Barriers to Student Persistence in Higher Education». [En línea], Santiago, disponible en http://didache. nazarene.org/index.php?option $=$ com_docman $\&$ task $=$ doc_ download\&gid=282\&Itemid=52 [Recuperado 17 de mayo de 2013].

Tinto, V., (1975) «Dropout in Higher Education: a Theoretical Synthesis of Recent Research», en Review of Educational Research. Vol. 45, No 1 , invierno, pp. 89-125. 
80 FACTORES ASOCIADOS A LA DESERCIÓN/RETENCIÓN DE LOS ESTUDIANTES MAPUCHE DE LA UNIVERSIDAD DE LA FRONTERA E INCIDENCIA DE LOS PROGRAMAS DE APOYO ACADÉMICO - S. Navarrete, R. Candia, R. Puchi

Wilmer, E., (2008) «Student Support Services for the Underprepared Student», en Inquiry. Vol. 13, Nº1, pp. 5-19.

Recibido: 19/08/2013

Aceptado: 07/11/2013 